\title{
Erratum
}

\section{paraChlorophenylalanine Potentiates Facilitatory Effects of Mescaline on Shuttlebox Escape/Avoidance in Rats}

\author{
DAVID M. STOFF, RICHARD J. WYATT, and J. CHRISTIAN GILLIN
}

Psychopharmacology 47, 287-292(1976)

Stephen H. Uretsky should be included as the second author. The authors should read:

\section{Control Mechanisms of Drinking}

Edited by G. Peters, J. T. Fitzsimons, L. Peters-Haefeli (This work was sponsored by the International Commission on the Physiology of Food and Fluid Intake)

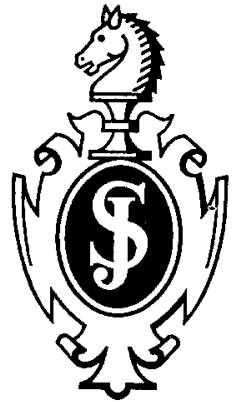

Springer-Verlag Berlin Heidelberg New York
136 figures. XIV, 210 pages. 1975

Cloth DM 64, 一; US \$26.20 ISBN 3-540-06828-7

Prices are subject to change without notice

The book contains papers reflecting the present state of research on the mechanisms regulating water intake. It is suggested that the renin-angiotensin system may act as a mediator of drinking responses evoked both tby peripheral stimulation and by stimulation within the brain. The authors discuss the relationships between intracellular thirst, hypovolemic thirst and the antidiuretic system, as well as the roles of intracerebral catecholaminergic and/or cholinergic systems. New results emphasize the importance of oropharyngeal factors in the control of water intake. 